\title{
Women's experiences and perceptions of induction of labour: Results from a German online-survey
}

\author{
Martina König-Bachmann ${ }^{1}$, Christiane Schwarz ${ }^{1}$, Christoph Zenzmaier ${ }^{1}$
}

\begin{abstract}
INTRODUCTION Induction of labour is common, with a large variety of indications and methods. Women's views and experiences still need to be explored in more depth. This study evaluated outcomes and childbirth experiences with different induction methods as perceived by women. METHODS A secondary data analysis of an online-survey with 698 participants comprising closed-ended and open-ended questions evaluating method and reason for induction, gestational age, mode of birth, assessment of received information, support and participation in decision-making, as well as the individual experience of labour and birth, was performed in 2015. Answers to open-ended questions were coded and assigned to main categories by inductive-content analysis. Subgroup analyses comparing frequencies of answer options or main categories dependent on induction methods and indications were conducted.

RESULTS Women frequently expressed a need for more information and participation, and reported negative childbirth experiences. Women being offered castor oil or other complementary and alternative methods less often lacked information. However, these methods were markedly less effective to induce labour, but when successful were associated with reduced rates of epidural pain relieve and caesarean sections. Moreover, compared with prostaglandins, complementary methods were associated with significantly more positive personal experiences and fewer burdensome or traumatic births.

concLusions Our findings revealed a substantial lack of information and participation associated with many women perceiving negatively labour and childbirth following induction. Adequate honest information that gives way to realistic expectations about labour induction and enablement of participation are important prerequisites to improve personal experience and need to be enhanced in order to raise childbirth satisfaction.
\end{abstract}

\section{AFFILIATION \\ 1 University of Applied Sciences Tyrol, Innsbruck, Austria \\ CORRESPONDENGE TO \\ Zenzmaier C. University of Applied Sciences Tyrol, Innsbruck, Austria. \\ E- mail: christoph.zenzmaier@ fhg-tirol.ac.at}

\section{KEYWORDS}

Induced labour, induction of labour, labour onset, participation, complementary alternative medicine, childbirth satisfaction

$\nabla$

Received: 12 April 2017

Revised: 12 June 2017

Accepted: 20 August 2017

\section{INTRODUCTION}

Induction of labour (IOL) is one of the most common interventions in high-income countries, concerning as many as one out of four pregnant women ${ }^{1}$. It may be performed for medical or non-medical reasons. There is ongoing debate on potential benefits and harms, depending on indication, method and timing. In Germany, like many other high income countries, induction is most frequently performed for "post-maturity"2. Compared with expectant management, a policy of labour induction at or beyond term may be associated with fewer perinatal deaths ${ }^{3}$. Similarly, randomized controlled trials and observational studies comparing elective (or non-medically indicated) IOL with expectant management demonstrated decreased risks of caesarean delivery and other maternal and neonatal morbidities after $\mathrm{IOL}^{4-6}$. In contrast, IOL at term was associated with an increased risk of adverse outcomes, in particular caesarean sections, when compared with spontaneous onset of labour at the same gestational week ${ }^{7-11}$, indicating that the outcome of observational studies largely depends on study design ${ }^{12,13}$.

IOL techniques comprise pharmacological medication, mechanical methods as well as alternative and complementary methods: such as castor oil, acupuncture, homeopathic methods or hypnotic relaxation ${ }^{14}$. Pharmacological IOL is well researched with oxytocin and the prostaglandins dinoprostone (PGE2) and misoprostol being the most 
commonly applied drugs ${ }^{14}$. Whereas oral misoprostol is not licensed for IOL in most countries, it is commonly used due to its relatively low price, uncomplicated storage and simple handling properties ${ }^{15}$. Moreover, randomised trials demonstrated that oral misoprostol is as effective as vaginal misoprostol at achieving vaginal birth and results in fewer caesarean sections than vaginal PGE2 or oxytocin ${ }^{15}$. However, several case reports have suggested that the rate of serious complications, such as excessive uterine contractions and rupture, may be increased by misoprostol in particular when applied vaginally, compared with other IOL methods ${ }^{16,17}$.

In 2015, IOL was performed in $21.8 \%$ ( $n=155,619)$ of all hospital births in Germany ( $n=715,574)$, with the most frequent indications being rupture of membranes (24.5\%) and post-term pregnancy (30.3\%), followed by placental dysfunction (6.6\%) and hypertensive disorders in pregnancy/pre-eclampsia $(4.9 \%)^{2}$. In $98.5 \%$ of the cases, induction was performed using pharmacological medication whereby the specific drug applied is not recorded in routine perinatal data documentation². However, in a recent national survey targeting registered departments of obstetrics and gynaecology in Germany, about two thirds of the respondents reported that they use misoprostol for IOL in viable term-pregnancies ${ }^{18}$.

Given the high efficiency of current IOL methods and the fact that induction at term is generally considered reasonably safe for both mother and child, IOL may be frequently performed for non-medical reasons or even on maternal request. However, a variety of adverse effects of IOL has been reported: including frustrating failures of induction, extremely fast and painful labour, increase in meconium staining, uterine hyperstimulation, uterine rupture, amniotic fluid embolism, maternal mortality, perinatal mortality and hypoxic ischemic encephalopathy ${ }^{19-22}$.

Women's views on IOL, their information needs, their preferences regarding IOL methods, and their experiences with induction have been not extensively evaluated yet. While women want to participate in decision-making ${ }^{23,24}$, they frequently expressed a need for more honest information on what to expect prior to induction ${ }^{19,21}$. IOL was associated with a less positive birth experience and women being less satisfied with aspects of their care ${ }^{19,21,25,26}$. Failed inductions not progressing to contractions/dilatation were experienced as wasted effort and pain, a feeling of having been let down, and disappointment ${ }^{26}$. In contrast, a Norwegian study by Heimstad et al. reported that women preferred IOL to serial antenatal monitoring beyond 41 weeks and had generally positive experiences with induction ${ }^{20}$.

In the German speaking European countries, antenatal care is mostly provided by obstetricians in private practice (including counselling for $I O L)$, although midwives may be involved in antenatal care if women wish so. Women receive care in a set schedule of five (Austria) to ten appointments (Germany and Switzerland). National obstetric guidelines are widely shared between the three countries, leading to a similar approach in care and clinical decision-making. Recently, Schwarz et al. published the first quantitative results of a German online-survey investigating women's perceptions of $\mathrm{IOL}^{27}$. Most women were induced with misoprostol or PGE2, and most frequent reasons for IOL were post-maturity, physician's recommendation and medical indications. Women indicated a high need for more information on alternatives to IOL, methods of IOL, side effects of the drugs and many would have wished for more support and time with decision-making ${ }^{27}$.

The present study represents a secondary data-analysis of the online-survey data from Schwarz et al. ${ }^{27}$, adding a subgroup analysis concerning IOL methods applied, as well as reasons for IOL. Additionally, this study provides a first analysis of the women's answers to openended questions on their experience of labour and birth included in the original survey.

\section{METHODS}

This secondary data-analysis is based on the dataset of the study from Schwarz et al. ${ }^{27}$ that was generated using an online questionnaire with ten questions. Women were asked in a structured paragraph of the survey: about the reason for IOL, method of IOL, gestational age, duration of IOL, mode of birth, and support with decision-making. Support was categorised as information needs (alternatives and medication), support with decision-making, participation, and time for decision-making. Two open questions concemed women's general experience with IOL. Ethical approval was obtained by the Hannover Medical School (No.2645-2015).

A total number of 698 women participated in the online-survey. In the course of data cleaning, 32 participants were excluded due to one of the following reasons: (i) questionnaire incomplete; no information of IOL method and reason for IOL, (ii) no IOL performed/IOL not successful, followed by spontaneous delivery $>5$ days after treatment was abandoned, (iii) experiences from more than one pregnancy merged in one form. From the remaining 666 participants, 607 respondents used computers with IP addresses located in Germany, 35 in Austria, 13 in Switzerland, 5 in other European countries and 6 in North America.

All closed-ended questions contained an option for additional comments, if required. Where possible, missing answers to closedended questions were deduced from the free text in the additional comments or the answers to the open-ended questions. For example, options to answer the closed-ended question on the reasons for IOL were: (i) "maternal request", (ii) "post-term", (iii) "medical reason”, (iv) "physician's recommendation”, (v) "midwife's recommendation” or (vi) "other: please specify". If women selected option (vi) whenever possible reasons were deduced from the free text and categorized accordingly: e.g. premature rupture of membranes, placental insufficiency, gestational diabetes or foetal death were categorized as (iii) "medical reason"; and "because I was urged to by doctors" as (iv) "physician's recommendation".

In the questionnaire, surveyed women could select which IOL methods had been offered to them and which were finally used. Selectable methods were: misoprostol, PGE2 vaginal inserts, castor oil, acupuncture, homoeopathy and clove oil, or "other methods". Given the low number of respondents with labour induction using acupuncture, homoeopathy or clove oil; these methods were summarized to complementary and alternative methods (CAM).

In the cases where more than one IOL method was used, the temporal sequence of treatments is not apparent from the survey data and it is not evident which method finally led to effective contractions. Thus, in subsequent analyses that compare IOL methods, only cases where labour was induced with one single method $(N=487)$ were included for analysis.

To accurately separate groups with different reasons for IOL, in subsequent analyses only those 511 (77\%) responders who stated just one single reason for IOL were included. Respondents' answers to an open-ended question on the individual experience of labour and birth were coded by inductive-content analysis. To enhance trustworthiness of the results, two researchers independently performed coding 
(investigator triangulation ${ }^{28,29}$ ). Subsequently, occasional differences in the researchers' conceptions were discussed and resolved in the research team and the codes were merged into the following main categories: (i) positive, (ii) neutral, (iii) exhausting, debilitating, lengthy, (iv) intense, fast / too fast, hyperactive, (v) painful, very painful, and (vi) burdensome, gruesome, traumatic.

Statistical differences were determined by Chi-square test and considered significant when $\mathrm{P}<0.05$.

\section{RESULTS}

Limited choice and lack of information on induction of labour methods

The IOL methods offered were specified by 615 out of 666 women (92\%) (Table 1). Misoprostol was most frequently reported ( $N=363$ ) followed by PGE2. A total of $70 \%$ of respondents reported that they were only offered one single method, in particular misoprostol and PGE2. Women who were offered castor oil or CAM were much more likely to have had several IOL methods at choice. caesarean section (12\%; $P=0.017)$. IOL with CAM resulted in a comparably low section rate $(P=0.051)$ but was associated with a high rate of operative vaginal deliveries (24\%; $P=0.078$ ). However, in total only 17 women had IOL with CAM as a single method resulting in a high statistical-fluctuation range in this group. Thus, in this subgroup only the rate of water births significantly differed from the total sample (18\% vs 4\%; P = 0.007).

Regarding pain management, women with IOL using castor oil used complementary pain management more frequently (16\%; P $=0.008$ ), whereas rates of epidural anaesthesia, and one or more injections, did not differ significantly between applied IOL methods (Table 4).

In total only $8 \%$ of responding women described their experience of labour and birth as positive and $14 \%$ had a neutral perception of labour/birth after IOL (Table 5). IOL with castor oil or CAM was associated with significantly more positive statements (18\%; P $=0.006$ and 29\%; $\mathrm{P}<0.001$, respectively). Approximately one third of women described labour/birth as "intense, fast, too fast or

Table 1. IOL methods offered and selected through the online-survey among women in 2015

\begin{tabular}{|c|c|c|c|c|c|c|c|c|c|c|c|c|c|c|c|c|c|c|}
\hline \multirow{2}{*}{$\begin{array}{c}\text { IOL } \\
\text { method }\end{array}$} & \multicolumn{2}{|c|}{ Offered } & \multicolumn{8}{|c|}{ \# Methods offered } & \multicolumn{2}{|c|}{ Selected } & \multicolumn{6}{|c|}{ \#Methods selected } \\
\hline & $\mathbf{N}$ & (\%) & 1 & (\%) & 2 & (\%) & 3 & (\%) & 4 & (\%) & $\mathbf{N}$ & (\%) & 1 & (\%) & 2 & (\%) & 3 & (\%) \\
\hline CAM & 106 & $(17.2)$ & 14 & $(13.2)$ & 57 & $(53.8)$ & 29 & $(27.4)$ & 6 & (5.7) & 64 & (11.4) & 17 & (26.6) & 35 & $(54.7)$ & 12 & (18.8) \\
\hline Castor oil & 126 & (20.5) & 34 & $(27.0)$ & 60 & $(47.6)$ & 26 & (20.6) & 6 & $(4.8)$ & 101 & (18.0) & 49 & $(48.5)$ & 40 & (39.6) & 12 & (11.9) \\
\hline PGE2 & 251 & $(40.8)$ & 148 & (59.0) & 79 & (31.5) & 18 & (7.2) & 6 & (2.4) & 166 & (29.6) & 137 & (82.5) & 21 & (12.7) & 8 & (4.8) \\
\hline Misoprostol & 363 & (59.0) & 233 & (64.2) & 98 & (27.0) & 26 & $(7.2)$ & 6 & (1.7) & 328 & $(58.5)$ & 273 & (83.2) & 48 & (14.6) & 7 & (2.1) \\
\hline $\begin{array}{l}\text { Total } \\
\text { sample }\end{array}$ & 615 & & 429 & (69.8) & 147 & (23.9) & 33 & (5.4) & 6 & (1.0) & 561 & & 476 & (84.8) & 72 & (12.8) & 13 & (2.3) \\
\hline
\end{tabular}

CAM: complementary and alternative methods; $N$ : number of respondents

Of the surveyed women 561 (84\%) specified the applied IOL methods and in $85 \%$ of reported cases one single IOL method was applied. Misoprostol and castor oil were offered and applied with similar frequencies (misoprostol: 59\% offered, 59\% applied; castor oil: $20 \%$ offered, $18 \%$ applied) indicating a high acceptance, whereas PGE2 and CAM were less frequently selected than offered. Misoprostol or PGE2 were commonly used as a single method, whereas $73 \%$ of women using CAM had to apply additional methods (Table 1). Prostaglandins were used in 75 out of 85 reported cases with more than one applied IOL method (Table 2).

Of the responding women, $60 \%$ stated that they would have liked more information on alternatives to induction (e.g. expectant management, watchful waiting) and 55\% more information on the drugs used. Women who had been offered CAM significantly less frequently complained about paucity of information. Moreover, the majority of the surveyed women would have needed more support, participation and time for decision-making (Table 3).

\section{Mode of birth and birthing experiences dependent on} induction of labour methods

Regarding the mode of delivery after IOL, $58 \%$ of all women reported normal vaginal delivery and $28 \%$ required a caesarean section (Table 4). Women who underwent IOL by castor oil required less frequently

\section{Table 2. Applied Combinations of IOL methods as identified} through the online survey

\begin{tabular}{ll}
\hline Combination & N \\
\hline CAM / Castor Oil & 10 \\
\hline CAM / PGE2 & 7 \\
\hline CAM / Misoprostol & 18 \\
\hline CAM / Castor Oil / PGE2 & 6 \\
\hline CAM / Castor Oil / Misoprostol & 5 \\
\hline CAM / PGE2 / Misoprostol & 1 \\
\hline Castor Oil / PGE2 & 7 \\
\hline Castor Oil / Misoprostol & 23 \\
\hline Castor Oil / PGE2 / Misoprostol & 1 \\
\hline PGE2 / Misoprostol & 7 \\
\hline Total & 85
\end{tabular}

hyperactive", irrespective of IOL method. $26 \%$ of the experiences were categorized as "painful or very painful", and 25\% even as "burdensome, gruesome or traumatic". Castor oil was associated with significantly less "painful or very painful" (12\%; P = 0.027) and "burdensome, gruesome or traumatic" experiences (12\%; P = 0.044), 

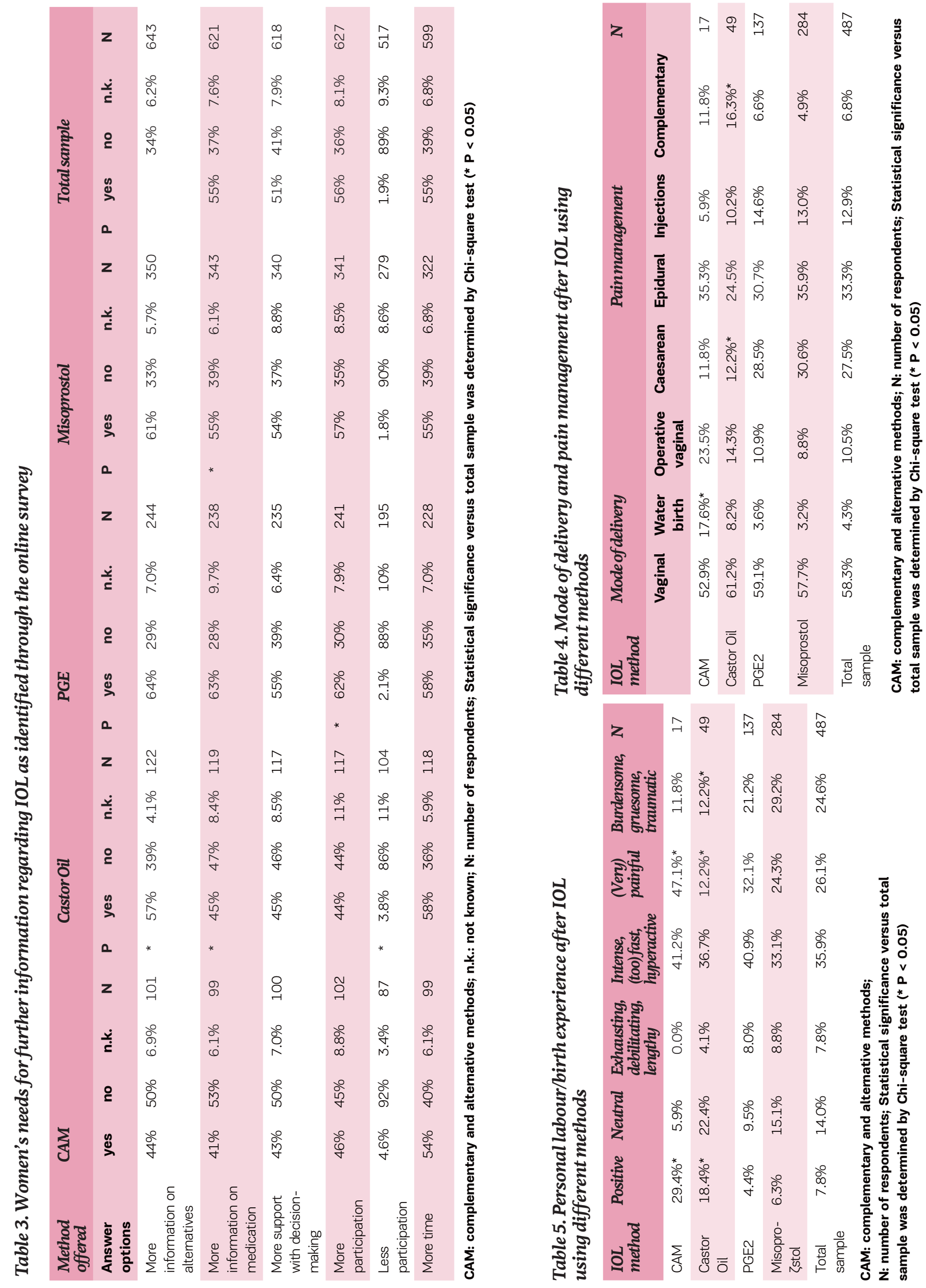


\section{Research paper}

Table 6. Gestational age at induction of labour

\begin{tabular}{lrrr|}
\hline Reasonfor IOL & Median & Range & N \\
\hline Maternal request & 40 & $36-42$ & 19 \\
\hline Post-term & 42 & $40-43$ & 202 \\
\hline Medical reason & 39 & $18-42$ & 191 \\
$\begin{array}{l}\text { Physician's } \\
\text { recommendation }\end{array}$ & 40 & $21-42$ & 92 \\
\hline $\begin{array}{l}\text { Midwife's } \\
\text { recommendation }\end{array}$ & 41 & $37-41$ & 7
\end{tabular}

$\mathrm{N}$ : number of respondents
Table 7. IOL method selected dependent on reasons for IOL

\begin{tabular}{|lccccc|}
\hline Reasonfor IOL & CAM & Castor Oil & PGE2 & Misoprostol & N \\
\hline Maternal request & $15.8 \%$ & $31.6 \% *$ & $26.3 \%$ & $36.8 \%$ & 19 \\
\hline Post-term & $9.4 \%$ & $16.3 \%$ & $21.3 \%$ & $50.0 \%$ & 202 \\
\hline Medical reason & $6.3 \%$ & $6.8 \% *$ & $28.8 \%$ & $49.7 \%$ & 191 \\
\hline $\begin{array}{l}\text { Physician's } \\
\text { recommendation }\end{array}$ & $5.4 \%$ & $10.9 \%$ & $27.2 \%$ & $46.7 \%$ & 92 \\
$\begin{array}{l}\text { Midwife's } \\
\text { recommendation }\end{array}$ & $0.0 \%$ & $42.9 \% *$ & $28.6 \%$ & $14.3 \%$ & 7 \\
\hline \begin{tabular}{l} 
Total sample \\
\hline
\end{tabular} & $7.6 \%$ & $12.7 \%$ & $25.4 \%$ & $48.3 \%$ & 511 \\
\hline
\end{tabular}

CAM: complementary and alternative methods; $\mathrm{N}$ : number of respondents; Statistical significance versus total sample was determined by Chi-square test $(* P<0.05)$

Table 8. Mode of delivery and pain management after IOL performed for different reasons

\begin{tabular}{|c|c|c|c|c|c|c|c|c|}
\hline \multirow[t]{2}{*}{ Reasonfor IOL } & \multicolumn{3}{|c|}{ Mode of delivery } & \multicolumn{4}{|c|}{ Painmanagement } & \multirow[t]{2}{*}{$\mathbf{N}$} \\
\hline & Vaginal & $\begin{array}{l}\text { Water } \\
\text { birth }\end{array}$ & $\begin{array}{l}\text { Operative } \\
\text { vaginal }\end{array}$ & Caesarean & Epidural & Injections & Complementary & \\
\hline Maternal request & $52.6 \%$ & $15.8 \% *$ & $10.5 \%$ & $31.6 \%$ & $47.4 \%$ & $5.3 \%$ & $5.3 \%$ & 19 \\
\hline Post-term & $60.4 \%$ & $2.0 \%$ & $15.3 \%$ & $26.2 \%$ & $37.6 \%$ & $15.3 \%$ & $7.9 \%$ & 202 \\
\hline Medical reason & $60.7 \%$ & $4.7 \%$ & $9.4 \%$ & $24.1 \%$ & $33.5 \%$ & $12.6 \%$ & $8.4 \%$ & 191 \\
\hline $\begin{array}{l}\text { Physician's } \\
\text { recommendation }\end{array}$ & $47.8 \% *$ & $2.2 \%$ & $14.1 \%$ & $30.4 \%$ & $35.9 \%$ & $13.0 \%$ & $3.3 \%$ & 92 \\
\hline $\begin{array}{l}\text { Midwife's } \\
\text { recommendation }\end{array}$ & $100.0 \% *$ & $28.6 \% *$ & $0.0 \%$ & $0.0 \%$ & $0.0 \% *$ & $14.3 \%$ & $28.6 \% *$ & 7 \\
\hline Total sample & $58.5 \%$ & $3.9 \%$ & $12.5 \%$ & $26.0 \%$ & $35.6 \%$ & $13.5 \%$ & $7.4 \%$ & 511 \\
\hline
\end{tabular}

$\mathrm{N}$ : number of respondents; Statistical significance versus total sample was determined by Chi-square test ( $\mathrm{P}<0.05)$

Table 9. Personal labour/birth experience after IOL performed for different reasons

\begin{tabular}{|c|c|c|c|c|c|c|c|}
\hline Reasonfor IOL & Positive & Neutral & $\begin{array}{l}\text { Exhausting, } \\
\text { debilitating, } \\
\text { lengthy }\end{array}$ & $\begin{array}{c}\text { Intense, (too) } \\
\text { fast, } \\
\text { hyperactive }\end{array}$ & $\begin{array}{l}\text { (Very) } \\
\text { painful }\end{array}$ & $\begin{array}{l}\text { Burdensome, } \\
\text { gruesome, } \\
\text { traumatic }\end{array}$ & $N$ \\
\hline Maternal request & $5.3 \%$ & $15.8 \%$ & $15.8 \%$ & $36.8 \%$ & $10.5 \%$ & $10.5 \%$ & 19 \\
\hline Post-term & $6.9 \%$ & $12.4 \%$ & $5.4 \%$ & $34.7 \%$ & $27.7 \%$ & $28.7 \%$ & 202 \\
\hline Medical reason & $6.8 \%$ & $15.2 \%$ & $9.9 \%$ & $34.0 \%$ & $24.1 \%$ & $24.1 \%$ & 191 \\
\hline $\begin{array}{l}\text { Physician's } \\
\text { recommendation }\end{array}$ & $8.7 \%$ & $7.6 \%$ & $13.0 \%$ & $35.9 \%$ & $26.1 \%$ & $26.1 \%$ & 92 \\
\hline $\begin{array}{l}\text { Midwife's } \\
\text { recommendation }\end{array}$ & $14.3 \%$ & $14.3 \%$ & $14.3 \%$ & $28.6 \%$ & $28.6 \%$ & $14.3 \%$ & 7 \\
\hline Total sample & $7.2 \%$ & $12.7 \%$ & $9.0 \%$ & $34.6 \%$ & $25.4 \%$ & $25.6 \%$ & 511 \\
\hline
\end{tabular}

$\mathrm{N}$ : number of respondents; Statistical significance versus total sample was determined by Chi-square test $\left({ }^{*} \mathrm{P}<0.05\right.$; no significant differences observed)

whereas CAM resulted in higher numbers of births experienced as painful or very painful (47\%; $P=0.049$; Table 5).

\section{Reasons for induction of labour}

The reason for using IOL was provided by 657 out of 666 (99\%) women. Frequencies of IOL reasons as well as gestational age at birth, as indicated by the responding women, are summarized in Table 6 .
IOL methods applied in each subgroup of IOL reasons are shown in Table 7. Women that underwent IOL on their own request significantly more frequently used castor oil (32\% vs $13 \% ; P=0.014$ ) and CAM (16\% vs $8 \%$, however not statistically significant) compared to the total sample. When labour was induced due to medical reasons, castor oil was used less frequently (7\% vs $13 \%$; $P=0.014)$. Use of castor oil was very frequent when IOL was performed following 
a midwife's recommendation, however the very low number of respondents in this group ( $N=7)$ limits the accuracy of this finding.

\section{Mode of birth and birthing experiences in relation to reason for induction of labour}

Rates of operative vaginal deliveries, caesarean sections and pain management did not differ significantly dependent on the reason for IOL stated (Table 8). Women who underwent IOL based on physician's recommendation significantly less frequently had a normal (vaginal) delivery (48\% vs 59\%; $\mathrm{P}=0.037$ ), while IOL on maternal request was associated with a higher rate of water births ( $16 \%$ vs $4 \%$; $P=$ 0.008). IOL after midwife's recommendation appeared to significantly affect several outcomes; however, these findings are probably not representative due to the low number of respondents in this subgroup $(\mathrm{N}=7)$.

Personal labour and birth experiences did not significantly differ dependent on the indicated reason for IOL (Table 9). There was a tendency that women who underwent IOL on maternal request less frequently perceived labour/birth as "painful or very painful" or as "burdensome, gruesome or traumatic", however, this tendency did not reach statistical significance.

\section{DISCusSION}

As reported by the surveyed women in our study, misoprostol and PGE2 were commonly used as a single method for IOL. In contrast, three out of four women using CAM applied additional induction methods. This finding is in line with the scarce evidence for CAM methods, like acupuncture or homoeopathy ${ }^{30,31}$. Similarly to previously reported efficiency of castor oil to initiate labour ${ }^{32,33}$, half of the women in our survey who took castor oil reported no additional used IOL methods. Women did not report on doses or application details regarding castor oil, but midwives in Germany very likely recommend a much lower dose (10 $\mathrm{mL}$ oil) than reported in the Cochrane review (30 $\mathrm{mL}$ oil), where castor oil proved to have frequently unpleasant side effects ${ }^{34-37}$.

As already highlighted in the publication by Schwarz et al. ${ }^{27}$, the majority of women who participated in this online-survey expressed a need for more information on alternatives and medication, more support with decision-making, and more participation. Consistently with this perceived lack on information, $70 \%$ of the women were only offered one single IOL method. Of note, castor oil and in particular CAM were less frequently offered without alternatives, indicating more comprehensive counselling. Women who were offered CAM significantly less often lacked information on alternatives and medication.

Adequate information that gives way to realistic expectations about childbirth and enablement of participation are important prerequisites to enhance personal control and self-efficacy, two major determinants of childbirth satisfaction ${ }^{38,39}$. It has been demonstrated that lower childbirth self-efficacy was associated with higher fear of childbirth, low childbirth knowledge, women preferring a caesarean section and higher rates of epidural anaesthesia ${ }^{39-41}$. Consistently, in the present study women induced with castor oil were significantly more satisfied with participation in decision-making, less frequently required epidural pain relieve and had a significantly reduced rate of caesarean sections. However, failed IOL with castor oil or CAM (which displayed a comparably low section rate) is likely to result in IOL using prostaglandins, whereas failed IOL with PGE2 or misoprostol probably more frequently leads to caesarean section without trying alternative IOL methods. Thus, the data restriction to women that used one single IOL method might have resulted in a selection bias towards births with fewer complications in the castor oil and CAM subgroups. Nevertheless, a reduced rate of caesarean sections was also observed in the full dataset without restriction to single IOL techniques, as reported previously ${ }^{27}$.

Moreover, IOL with castor oil or CAM was associated with significantly more positive personal labour/birth experiences and fewer births perceived as burdensome, gruesome or traumatic. These findings could be on the one hand again a result from enhanced personal control and self-efficacy, and on the other hand might be in part due to the same selection bias discussed above; while the lower rate of burdensome or even traumatic birth experiences might reflect the lower rate of caesarean sections in these subgroups. Interestingly, castor oil more rarely resulted in (very) painful labour/birth, whereas almost $50 \%$ of the birth experiences provided by women induced with CAM fell into this category.

As expected, the main single indications for IOL were post-maturity and medical reasons. The use of castor oil in IOL due to medical reasons was scarce, indicating that this method is uncommon in secondarycare settings. In contrast, while only few women had IOL on their own request, approximately 30\% of this group used castor oil. Given the high availability of castor oil, this indicates that a significant proportion of women use this for self-medication to induce labour without indication. Thus, midwives and physicians should counsel pregnant women accordingly, that IOL even with a "natural compound" is a nonphysiological intervention that should not be performed without clear indication and without supervision by a healthcare professional.

The fact that only about $20 \%$ of the women who participated in the survey experienced labour and birth as being positive or neutral, and that $25 \%$ perceived it as burdensome, gruesome or even traumatic is very worrying. This clearly indicates that childbirth experience (following IOL) often is in total contrast to what women expected. Unfortunately, the data form the online-survey did not contain a control group with spontaneous onset of labour. Thus, it is unclear if this discrepancy between childbirth experience and expectation is associated with IOL or is a general phenomenon. However, this finding again highlights the need for honest information on what to expect about childbirth in order to enhance personal control and self-efficacy and ultimately childbirth satisfaction $^{38,39}$.

\section{Limitations}

This study has several limitations, as was in part already outlined in the first publication from this survey ${ }^{27}$. The study design of an online-survey does not allow one to check whether the sample is representative for the average German-speaking population and thus the authors do not claim the sample as being representative. However, some sample characteristics such as IOL methods used, reason for IOL and gestational age at induction were comparable to the German national dataset ${ }^{27,42}$. Moreover, other relevant or interesting information was not collected, such as women's ages, socio-economic status or education, and parity. There was no possibility to select or specify other IOL methods, such as mechanical methods or oxytocin, which potentially excluded part of the women from sharing their IOL experiences. However, the use of mechanical methods in Germany is marginal since $98.5 \%$ of inductions are performed using pharmacological medication ${ }^{42}$. Oxytocin as a selectable option, for the IOL method used, might have significantly increased the number of women reporting more than one single IOL method. However, since Oxytocin is commonly used for augmentation of labour, there is the possibility that some women mistakenly 


\section{Research paper}

reported Oxytocin as an additional IOL method. Another limitation is the possibility of a recall bias. In particular, since the findings of the study indicate a perceived lack of information and participation, some women might have been misinformed or misinterpreted interventions/ medication. For example, in the PGE2 group, where $63 \%$ of women stated that they missed sufficient information on the drugs used, it is possible that some might have been induced with other drugs, such as vaginally applied misoprostol and not PGE2.

Investigator triangulation was used to enhance trustworthiness of the qualitative component of this study, whereby two researchers independently performed coding. Triangulation by more than two researchers might have decreased residual researcher bias to a greater extend. However, differences in the two researchers' assignments of statements to the generated main categories were rare and were discussed and resolved within the research team, in order to ensure trustworthiness of the findings.

There is also the possibility that women who decided to participate in the survey may have been rather disappointed with their inductions and may have been particularly keen on sharing their less favourable experiences. Indeed, the high rate of non-elective caesarean sections of more than $25 \%$ exceeds the national German average ${ }^{42}$. However, this finding is in line with previous reports that IOL at term is associated with an increased risk of caesarean sections when compared with spontaneous onset of labour ${ }^{7-11}$.

\section{CONGLUSIONS}

Collectively, the findings from an online-survey indicate that participating women perceived PGE2 and misoprostol similarly effective in inducing labour leading to a comparable rate of positive and negative labour/ birth experiences. Castor oil, and in particular CAM, were markedly less effective to induce labour; however, in the case of an effective IOL, labour/birth was more often perceived to be a positive experience compared to induction achieved using prostaglandins. In general, labour and birth was frequently experienced negatively. Women reported a substantial lack of information and participation, potentially limiting personal control and self-efficacy, two major determinants of childbirth satisfaction.

\section{REFERENGES}

1. World Health Organization. WHO recommendations for induction of labour; 2011.

2. InstitutfürQualitätssicherungundTransparenzimGesundheitswesen. Ergebnisse für das Erfassungsjahr 2015 - Geburtshilfe. Berlin; 2016.

3. Gülmezoglu AM, Crowther CA, Middleton P, Heatley E. Induction of labour for improving birth outcomes for women at or beyond term. Cochrane Database Syst Rev. 2012:CD004945. doi:10.1002/14651858.CD004945.pub3.

4. Saccone G, Berghella V. Induction of labor at full term in uncomplicated singleton gestations: a systematic review and metaanalysis of randomized controlled trials. Am J Obstet Gynecol. 2015;213:629-36. doi:10.1016/j.ajog.2015.04.004.

5. Darney BG, Snowden JM, Cheng YW, Jacob L, Nicholson JM, Kaimal $A$, et al. Elective induction of labor at term compared with expectant management: matemal and neonatal outcomes. Obstet Gynecol. 2013;122:761-9. doi:10.1097/AOG.0b013e3182a6a4dO.
6. Gibson KS, Waters TP, Bailit JL. Maternal and neonatal outcomes in electively induced low-risk term pregnancies. Am J Obstet Gynecol. 2014;211:249.e1-249.e16. doi:10.1016/j.ajog.2014.03.016.

7. Zenzmaier C, Leitner H, Brezinka C, Oberaigner W, König-Bachmann M. Maternal and neonatal outcomes after induction of labor: a population-based study. Arch Gynecol Obstet. 2017. doi:10.1007/s00404-017-4354-4.

8. Glantz JC. Elective induction vs. spontaneous labor associations and outcomes. J Reprod Med. 2005;50:235-40.

9. Bailit JL, Gregory KD, Reddy UM, Gonzalez-Quintero VH, Hibbard JU, Ramirez MM, et al. Maternal and neonatal outcomes by labor onset type and gestational age. Am J Obstet Gynecol. 2010;202:245. e1-245.e12. doi:10.1016/j.ajog.2010.01.051.

10. Grivell RM, Reilly AJ, Oakey H, Chan A, Dodd JM. Maternal and neonatal outcomes following induction of labor: a cohort study. Acta Obstet Gynecol Scand. 2012;91:198-203. doi:10.1111/j.1600-0412.2011.01298.x.

11. Caughey AB, Sundaram V, Kaimal AJ, Gienger A, Cheng YW, McDonald KM, et al. Systematic review: elective induction of labor versus expectant management of pregnancy. Ann Intern Med. 2009;151:252-63, W53-63.

12. Darney BG, Caughey AB. Elective induction of labor symposium: nomenclature, research methodological issues, and outcomes. Clin Obstet Gynecol. 2014;57:343-62. doi:10.1097/GRF.0000000000000029.

13. Glantz JC. Elective induction of labor at term compared with expectant management: maternal and neonatal outcomes. Obstet Gynecol. 2014;123:363. doi:10.1097/AOG.0000000000000114.

14. Mozurkewich EL, Chilimigras JL, Berman DR, Perni UC, Romero VC, King VJ, et al. Methods of induction of labour: a systematic review. BMC Pregnancy Childbirth. 2011;11:84. doi:10.1186/1471-2393-11-84.

15. Alfirevic Z, Aflaifel N, Weeks A. Oral misoprostol for induction of labour. Cochrane Database Syst Rev. 2014:CDO01338. doi:10.1002/14651858.CD001338.pub3.

16. Sanchez-Ramos L, Kaunitz AM, Wears RL, Delke I, Gaudier FL. Misoprostol for cervical ripening and labor induction: a metaanalysis. Obstet Gynecol. 1997;89:633-42. doi:10.1016/S0029-7844(96)00374-2.

17. Chen W, Xue J, Peprah MK, Wen SW, Walker M, Gao Y, et al. A systematic review and network meta-analysis comparing the use of Foley catheters, misoprostol, and dinoprostone for cervical ripening in the induction of labour. BJOG. 2016;123:346-54. doi:10.1111/1471-0528.13456.

18. Voigt F, Goecke TW, Najjari L, Pecks U, Maass N, Rath W. Off-label use of misoprostol for labor induction in Germany: a national survey. Eur J Obstet Gynecol Reprod Biol. 2015;187:85-9. doi:10.1016/j.ejogrb.2014.11.026.

19. Shetty A, Burt R, Rice P, Templeton A. Women's perceptions, expectations and satisfaction with induced labour--a questionnairebased study. Eur J Obstet Gynecol Reprod Biol. 2005;123:56-61. doi:10.1016/j.ejogrb.2005.03.004.

20. Heimstad R, Romundstad PR, Hyett J, Mattsson L, Salvesen KA. Women's experiences and attitudes towards expectant management and induction of labor for post-term pregnancy. Acta 


\section{Research paper}

Obstet Gynecol Scand. 2007;86:950-6. doi:10.1080/00016340701416929.

21. Gatward H, Simpson M, Woodhart L, Stainton MC. Women's experiences of being induced for post-date pregnancy. Women Birth. 2010;23:3-9. doi:10.1016/j.wombi.2009.06.002.

22. Wagner M. Off-label use of misoprostol in obstetrics: a cautionary tale. BJOG. 2005;112:266-8. doi:10.1111/j.1471-0528.2004.00445.x.

23. Emslie MJ, Campbell MK, Walker KA, Robertson S, Campbell A. Developing consumer-led matemity services: a survey of women's views in a local healthcare setting. Health Expect. 1999;2:195207.

24. Taylor SJ, Armour CL. Measurement of consumer preference for treatments used to induce labour: a willingness-to-pay approach. Health Expect. 2000;3:203-16.

25. Hildingsson I, Karlström A, Nystedt A. Women's experiences of induction of labour--findings from a Swedish regional study. Aust N Z J Obstet Gynaecol. 2011;51:151-7. doi:10.1111/j.1479-828X.2010.01262.x.

26. Henderson J, Redshaw M. Women's experience of induction of labor: a mixed methods study. Acta Obstet Gynecol Scand. 2013;92:1159-67. doi:10.1111/aogs.12211.

27. Schwarz C, Gross MM, Heusser P, Berger B. Women's perceptions of induction of labour outcomes: Results of an online-survey in Germany. Midwifery. 2016;35:3-10. doi:10.1016/j.midw.2016.02.002.

28. Golafshani N. Understanding reliability and validity in qualitative research. The qualitative report. 2003;8:597-606.

29. Williamson GR. Illustrating triangulation in mixed-methods nursing research. Nurse Res. 2005;12:7-18.

30. Smith CA, Crowther CA, Grant SJ. Acupuncture for induction of labour. Cochrane Database Syst Rev. 2013:CD002962. doi:10.1002/14651858.CD002962.pub3.

31. Smith CA. Homoeopathy for induction of labour. Cochrane Database Syst Rev. 2003:CD003399. doi:10.1002/14651858.CD003399.

32. Garry D, Figueroa R, Guillaume J, Cucco V. Use of castor oil in pregnancies at term. Altern Ther Health Med. 2000;6:77-9.

33. Azhari S, Pirdadeh S, Lotfalizadeh M, Shakeri MT. Evaluation of the effect of castor oil on initiating labor in term pregnancy. Saudi Med J. 2006;27:1011-4.

34. Kelly AJ, Kavanagh J, Thomas J. Castor oil, bath and/or enema for cervical priming and induction of labour. Cochrane Database Syst Rev. 2013:CD003099. doi:10.1002/14651858.CD003099.pub2.

35. Kehl S, Welzel G, Ehard A, Berlit S, Spaich S, Siemer J, et al. Women's acceptance of a double-balloon device as an additional method for inducing labour. Eur J Obstet Gynecol Reprod Biol. 2013;168:30-5. doi:10.1016/j.ejogrb.2012.12.018.

36. Kehl S, Faschingbauer F, Beckmann MW, Dammer U. Methoden zur Geburtseinleitung: Vorteile und Risiken individuell abwägen. Hebamme. 2016;29:177-180. doi:10.1055/s-0042-108395.

37. Fendesack I. Rizinusöl - eine kontrovers diskutierte Methode zur Geburtseinleitung. Hebamme. 2013;26:228-232. doi:10.1055/s-0033-1345498.
38. Christiaens W, Bracke P. Assessment of social psychological determinants of satisfaction with childbirth in a cross-national perspective. BMC Pregnancy Childbirth. 2007;7:26. doi:10.1186/1471-2393-7-26.

39. Carlsson I, Ziegert K, Nissen E. The relationship between childbirth self-efficacy and aspects of well-being, birth interventions and birth outcomes. Midwifery. 2015;31:1000-7. doi:10.1016/j.midw.2015.05.005.

40. Salomonsson B, Gullberg MT, Alehagen S, Wijma K. Self-efficacy beliefs and fear of childbirth in nulliparous women. J Psychosom Obstet Gynaecol. 2013;34:116-21. doi:10.3109/0167482X.2013.824418.

41. Schwartz L, Toohill J, Creedy DK, Baird K, Gamble J, Fenwick $J$. Factors associated with childbirth self-efficacy in Australian childbearing women. BMC Pregnancy Childbirth. 2015;15:29. doi:10.1186/s12884-015-0465-8.

42. AQUA-Institut. Quality indicators. National data evaluation 2014 period: Obstetrics. Göttingen; 2015.
ACKNOWLEDGMENTS

The authors would like to thank all mothers who completed the online questionnaire.

\section{CONFLIGT OF INTERESTS} The authors have completed and submitted the ICMJE Form for Disclosure of Potential Conflicts of Interest and none was reported.

\section{FUNDING}

There was no source of funding for this research.

PROVENANGE AND PEER REVIEW

Not commissioned; Externally peer reviewed 